\title{
Saúde Institucional: Proposta de Atuação em Instituições Educacionais
}

\author{
Allan Martins Mohr \\ Aurea Cristina Magalhães Niada \\ Carla de Oliveira Vaz Chiarello \\ Luciana Albanese
}

\section{RESUMO}

Este artigo tem por objetivo relatar a atuação de uma equipe multiprofissional de promoção de saúde institucional em um curso de graduação do tipo bacharelado, especificamente um bacharelado "não-engenharia", em uma Instituição Federal de Ensino Superior (IFES) no sul do Brasil. Almejando alcançar o objetivo proposto, é apresentado um recorte da prática de diagnóstico institucional realizada no primeiro semestre do ano de 2019 pela Comissão de Saúde Institucional da IFES em tela especificando as etapas de observação participante, entrevistas e elaboração da hipótese diagnóstica e proposta de intervenção. Nessa experiência, pudemos concluir que é possível a realização de um trabalho de saúde institucional pautada nos pressupostos da Psicologia Institucional a ser desenvolvido por uma equipe multiprofissional e construída com membros de uma mesma organização, porém com algumas ressalvas. Ressaltamos, entre elas, a importância do estudo teórico contínuo, reuniões permanentes da equipe executora e uma supervisão capacitada para que a equipe não se identifique com o sintoma a ser estudado, com o sofrimento, tampouco os fenômenos de grupo da instituição a ser diagnosticada.

Palavras-chave: Educação; Instituições de Ensino Superior; Psicologia Institucional.

\section{ABSTRACT}

\section{Acting Proposal in Educational Institutions Saúde Institucional}

This article aims to report the performance of a multi-professional institutional health promotion team in a bachelor's degree, particularly a non-engineering bachelor's degree, in a Federal Higher Education Institution (FHEI) in southern Brazil. Aiming to achieve the proposed objective, is presented a clipping of the practice of institutional diagnosis performed in the first semester of 2019 by the FHEI Institutional Health Commission, specifying the stages: participant observation, interviews, the diagnostic hypothesis elaboration, and intervention proposal. In this experience, we could conclude that it is possible to perform institutional health work based on the assumptions of Institutional Psychology to be developed by a multi-professional team and built with members of the same organization, but with some caveats. Among them, we emphasize the importance of the continuous theoretical study, consecutive meetings of the executing team, and qualified supervision so that the team does not identify itself with the symptom to be studied, with the suffering, nor the group phenomena of the institution to be diagnosed.

Keywords: Education; Higher Education Institutions; Institutional Psychology.

Este artigo tem por objetivo relatar a atuação de uma equipe multiprofissional de promoção de saúde institucional em um curso de graduação do tipo bacharelado em uma Instituição Federal de Ensino Superior (IFES) no sul do Brasil. Da instituição analisada, constam em torno de 450 discentes distribuídos em dez períodos do curso e 23 docentes (entre servidores e substitutos). Ato contínuo, este trabalho apresenta o resultado de um desafio aceito por nove servidores

\section{Sobre os autores}

A. M. M.

0000-0002-5764-9623

Universidade Tecnológica Federal do Paraná - Curitiba-PR mohr@utfpr.edu.br

\section{A. C. M. N.}

0000-0002-9026-0054

Universidade Tecnológica Federal do Paraná - Curitiba-PR

aureaniada@utfpr.edu.br

\section{O. V. C.}

0000-0002-1350-5935.

Universidade Tecnológica Federal do Paraná - Curitiba-PR carlachiarello@utfpr.edu.br

\section{A.}

0000-0001-5303-8086.

Universidade Federal do Paraná

- Curitiba-PR

lu5valore@gmail.com

\section{Direitos Autorais}

Este é um artigo de acesso aberto e pode ser reproduzido livremente, distribuído, transmitido ou modificado, por qualquer pessoa desde que usado sem fins comerciais. 0 trabalho é disponibilizado sob a licença Creative Commons CC-BY-NC.

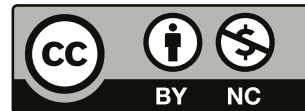


públicos federais, lotados em uma IFES, em pensar relações de trabalho descritas pelos atores institucionais como "muito sofridas" e propor alternativas para a análise de um sofrimento que, conforme descrito, estava instituído há longos anos; além de sua possível superação.

Não obstante, cabe dizer que este relato de experiência não prioriza o aprofundamento teórico, senão descrever o que pode ser apreendido inicialmente de um trabalho institucional desde dentro da própria instituição; atuação cujo foco se organizou com o objetivo de promover saúde mental e institucional por meio do estudo das relações inerentes a um grupo; relações de grupo, "mas não aquelas imediatamente observáveis, e sim, tal como percebidas, imaginadas, por aqueles que concretamente a fazem" (Guirado, 2009b, p. 329).

Assim, é à sombra desse cenário que se instalou na IFES em tela a Comissão de Saúde Institucional (doravante denominada CSI) em 2019. A referida Comissão fora composta, desde seu início, por nove servidores, a saber: dois psicólogos, dois pedagogos, dois professores, um assistente social e dois técnicos administrativos, sendo um deles cientista social e o segundo bacharel em gestão pública.

\section{A DEMANDA}

Em fevereiro de 2019, a Diretoria de Graduação da IFES supracitada entrou em contato com o psicólogo da universidade para conversar sobre um dos cursos de bacharelado da instituição. Na ocasião, comentou-se das inúmeras demandas que vem surgindo há tempos por parte dos estudantes e dos professores; demandas que denotavam, segundo a conclusão da reunião, um sofrimento instalado no curso e que circundava todos os níveis hierárquicos e os atores institucionais. Da parte dos professores, os docentes relataram a presença de comportamentos hostis e imaturidade dos estudantes; por parte do alunado, os discentes se queixaram da falta de acolhimentos de suas demandas por parte dos professores; além de considerações sobre a relação professor-aluno que seria empobrecida e causadora de mal estar. Foi apresentada, então, a proposta de um trabalho em Saúde Institucional que pretenderia analisar, pautado nos estudos da Psicologia Institucional (Bleger, 1984; Guirado, 2009a), as relações existentes na instituição visando à melhoria dos relacionamentos entre os atores institucionais.

Ao apresentar a proposta e os pressupostos do trabalho, a saber, um diagnóstico institucional e uma futura intervenção, foi agendada nova reunião com a Diretoria de Graduação a fim de elaborar um plano de atuação em Saúde Institucional para com o curso em tela. Nessa primeira reunião, foi descrito o trabalho em Psicologia Institucional e um projeto para capacitação de uma equipe em Saúde Institucional com a intenção de formar uma Comissão de Saúde Institucional que realizaria o trabalho. O projeto "Capacitação: Programa de Promoção de Saúde Institucional" foi elaborado e se iniciou o processo de contratação de uma capacitadora em Psicologia Institucional. O papel da capacitação foi instrumentalizar os membros da CSI com os pressupostos da psicologia institucional sem exigir deles, todavia, que fossem ou realizassem o trabalho de um psicólogo. Além da capacitação teórica, o trabalho da capacitadora foi o de supervisionar a equipe no trabalho diagnóstico, possibilitando uma tarefa mais focada e eticamente aprimorada. É mister ressaltar que desde o início desta intervenção um cuidado ético foi tomado em não misturar as atividades restritas ao profissional psicólogo com a atuação da Comissão. Os membros estavam advertidos da distinção entre os trabalhos, mas estavam cientes, também, que o caráter multiprofissional da equipe trazia vantagens ímpares para a tarefa, como singularidades de escuta e vertentes distintas para futuras intervenções.

Em seguida, a equipe se reuniu com a capacitadora para uma primeira apresentação e início das atividades de capacitação/orientação da tarefa. Alguns dias depois, a CSI se reuniu pela primeira vez com o curso no qual seria realizado o trabaIho. Nessa reunião estavam presentes a Direção de Graduação, os membros da comissão, os docentes e a coordenação do curso, além da chefia de departamento sob o qual o curso está instalado. Após a exposição das demandas existentes, e que levaram à construção da proposta de trabalho em saúde institucional, foi autorizado unanimemente pelos professores, o trabalho da CSI.

\section{A EXPERIÊNCIA}

Antes de passar ao relato da experiência propriamente dita, cabe ratificar que o objetivo deste trabalho foi estudar as relações imanentes à instituição que, conforme entendemos a partir dos estudos de Bleger (1984), Guirado (2009a) e Pichón-Rivière (2005), pode ser descrita como um grupo organizado de pessoas a gerar, conseguintemente a essa organização, uma supraestrutura que o sistematiza para além do organograma, e o estrutura discursivamente; em outras palavras, instituição fora entendida por essa CSI como o organismo formado pelas relações de atores que pertencem a um mesmo ambiente discursivo, por exemplo: um curso, um departamento, um núcleo ou, ainda, uma diretoria e um campus. Em outras palavras, instituição é a estrutura criada a partir das relações entre os atores institucionais (Viaro et al., 2016) ou, ainda, conforme nos explica Guirado: a estrutura organizada a partir das "práticas ou relações sociais que se repetem e se legitimam, na ação mesma de seus autores" (2015, p. 108). Válido é ressaltar também que esta Comissão não se propôs, tampouco teve por objetivo analisar individualmente comportamentos dos membros de uma instituição, uma vez que, de acordo com a pers- 


\section{M." INTERACÃO EM PSICOLOGIA}

pectiva metodológica adotada, o foco consistiu em pensar as relações que acontecem entre os atores institucionais. Dessa forma, podemos dizer que instituição é um discurso construído e constituído pela dinâmica entre os atores institucionais. Nas palavras de Guirado, apoiando-se nos estudos de Guilhon de Albuquerque, lemos ademais que instituição pode ser pensada como a legitimação, por repetição, de uma soma de relações sociais. Assim, "essa legitimação se dá, em ato, pelos efeitos de reconhecimento de que essas relações são óbvias e que naturalmente sempre foram assim. Dá-se, ao mesmo tempo e complementarmente, pelos efeitos de desconhecimento de sua relatividade" (Guirado, 2009a, p. 36). Para além dessa conceituação, cabe descrever que se compreendeu a atuação institucional no sentido de uma investigação de fenômenos que ocorrem na relação entre sujeitos de uma instituição. Por conseguinte, no trabalho em saúde institucional se pressupõe investigar os fenômenos decorrentes das interações humanas, uma atuação em "que gradualmente tem lugar uma meta-aprendizagem que consiste em que os implicados na tarefa aprendem a observar e refletir sobre os acontecimentos e a encontrar seu sentido, seus efeitos e integrações" (Bleger, 1984, p. 47).

Posto isso, o trabalho realizado pela Comissão nesse primeiro ano de suas atividades se concentrou em um único curso e teve no primeiro semestre a característica de um diagnóstico institucional; diagnóstico que tinha como objetivo estudar as relações institucionais, aproximar a equipe da Comissão e propor, ao final do semestre, uma possibilidade de intervenção. Assim, o diagnóstico institucional foi realizado se pautando nas seguintes atividades: reuniões, observações e entrevistas semiestruturadas. Acerca das reuniões, foram duas com a direção da universidade, uma reunião com a coordenação do curso e chefia do departamento, duas reuniões exclusivas com o professorado, uma reunião com alunos e professores, três reuniões exclusivas com o grupo discente (primeiro período, nono período e Centro Acadêmico) e, em paralelo, oito encontros de capacitação da equipe da comissão. Além dessas reuniões de construção dos dados a serem analisados, realizamos três entrevistas devolutivas no final do semestre, uma com a direção, coordenação de curso e chefia do departamento, outra com os docentes e a terceira com os estudantes do curso.

Sobre a primeira etapa do trabalho de diagnóstico denominamos observação participante e teve por objetivo o início da construção dos dados que serviram como base integrante do diagnóstico institucional. Nesse sentido, a observação visou promover uma diluição das resistências ao trabalho favorecendo uma aproximação e a construção de uma transferência de trabalho entre a instituição analisada e os membros da equipe da Comissão; até porque uma proposta de atuação institucional pode gerar resistências fortíssimas em alguns grupos
(Acevedo, 2016). A transferência, empatia e confiança entre as partes são de extrema importância para que o trabalho de diagnóstico e, posteriormente, o trabalho de intervenção possa ser realizado com o mínimo de resistência possível. A bem da verdade, a relação transferencial positiva é de importância radical para que o trabalho seja factível, uma vez que uma transferência negativa, agressiva, impede o bom desenrolar das atividades (Freud, 1912/1996a; 1917 [1916-17]/1996b).

Assim, oficialmente iniciada em 27/05/2019 - após a reunião com os estudantes do curso na qual se apresentou a equipe de trabalho da CSI, enquadrou-se a tarefa e o trabalho diagnóstico foi aceito e autorizado pela instituição como um todo (agora também pelos alunos) - a observação participante consistiu na vivência dos membros da CSI na vida da instituição, seus espaços, salas de aula, intervalos e conversas. Participamos do espaço do Centro Acadêmico, de algumas salas de aula e conversas de corredor, da sala dos professores, dos cafés dos docentes e dos espaços de laboratório. Desse momento da tarefa, recolhemos algumas experiências de acolhimento por parte da instituição, bem como percebemos alguns incômodos e resistências que, entendemos, é parte inicial de toda tarefa diagnóstica. Em pouquíssimos momentos sentimos agressividade por parte dos atores institucionais, o que denotou à equipe da CSI que sua aproximação e pertencimento à instituição estava sendo bem acolhida. Em relação às entrevistas, elas foram realizadas a partir de 10/05/2019 e tiveram como objetivo aprofundar os dados construídos desde as reuniões iniciais, somados àqueles da observação participante. As entrevistas foram realizadas de maneira semiestruturada, com um tema central específico, a saber: a relação entre os atores institucionais. Dessa forma, montamos a etapa de entrevistas com os seguintes instrumentos: entrevistas individuais (docentes e discentes); entrevistas em pequenos grupos (até 3 discentes); entrevistas de turmas (reuniões com $1^{\circ}$ período, $9^{\circ}$ período e Centro Acadêmico); e questionário aberto encaminhado por e-mail para todos os atores institucionais.

Sobre as entrevistas semiestruturadas, utilizamo-nos dos seguintes itens para estudo - lembrando que, justamente por ser uma entrevista não-estruturada, muitas vezes não foi realizada a pergunta específica, mas a resposta fora recortada do material produzido durante a entrevista. Com os alunos, focamos os temas: como veem o curso; como veem os professores; como se veem como alunos; como se veem vistos como alunos; como percebem a relação entre alunos; como percebem a relação entre os professores; quais os aspectos favoráveis do curso; e quais os aspectos dificultadores do curso. Por sua vez, nas entrevistas com os docentes, estudamos: como veem os alunos; como se veem como professores; como se veem vistos como professores; como percebem a relação entre os alunos; como percebem a relação entre os professores; quais os aspectos favoráveis do curso; e quais os aspectos 


\section{dificultadores.}

Diferente dos alunos, os docentes foram convidados a participarem das entrevistas de maneira exclusivamente individual - foram convidados pessoalmente e por e-mail. Ao todo foram dezoito (18) docentes entrevistados (de um total de 23 professores). Em relação aos estudantes, escutaram-se dois períodos inteiros do curso, primeiro e nono, além do Centro Acadêmico. Também foram feitas quarenta e uma (41) entrevistas com estudantes ${ }^{1}$ - válido considerar, também, que por duas semanas passamos em salas de aula convidando os estudantes para participarem das entrevistas com a equipe da CSI, além de e-mails direcionados aos discentes com o mesmo intuito. Por fim, recolhemos dez (10) respostas ao questionário aberto encaminhado aos integrantes da instituição exclusivamente por meio eletrônico.

\section{HIPÓTESE DIAGNÓSTICA E PROPOSTA DE INTERVENÇÃO}

Considerando os dados construídos pela observação participante e as entrevistas, pudemos construir uma hipótese diagnóstica acerca do sofrimento relatado pelos atores institucionais ao longo de todo o trabalho. Em sequência, foi elaborado também um plano de intervenção que, entendeu-se, contemplaria as necessidades levantadas pelo trabalho diagnóstico. Não obstante, cabe antes dizer que a hipótese elaborada foi resultado de uma construção, um trabalho de escuta que se iniciou nas primeiras reuniões com a direção e no enquadramento da tarefa com os atores institucionais. Quando do enquadramento, pode-se escutar duas expectativas distintas, a saber, por parte do alunado, um anseio de punição em relação a alguns professores; da parte dos docentes, certa ambivalência evidenciada por medo e alívio. Medo porquanto alguns entendiam o trabalho da Comissão como um reforço da IFES à fala dos alunos contra os professores e um alívio, por parte de outros, por finalmente estarem sendo escutados pela instituição em seu sofrimento.

É fato que "toda instituição enfrenta, inevitavelmente, mudanças e conflitos ao longo do tempo, uma vez que o distanciamento de sua origem e seu crescimento introduzem demandas que exigem novos critérios e estratégias" (Plut, 2016, p. 86, tradução nossa), mas é importante retomar que ao longo de todo o trabalho realizado pela CSI o significante "sofrimento" se repetiu de maneira significativamente soberana. Portanto, a partir dessa constatação, a Comissão propôs a análise do discurso escutado sustentando uma hipótese diagnóstica costurada com três eixos de estudo. 0 primeiro eixo condensou o seguinte raciocínio: etiologia do sofrimento pautada na história e cultura do curso, porquanto sua história se baseia na construção de um departamento a partir da cisão com um departamento anterior e em uma cultura do sofrimento que repete a cultura de sofrimento do ensino superior nacional. Tal história criou uma instituição não homogênea, com relações interpessoais sofridas tanto no grupo de estudantes quanto no professorado. Cabe ressaltar que a história de um grupo, meIhor, de uma instituição, é de extrema importância na atuação em psicologia institucional; afinal, como nos lembra Acevedo: a equipe que atua com psicologia institucional deve se lembrar de que, ao acolher uma demanda, estão "se introduzindo na trama de uma história tanto cronológica como mítica" (2016, p. 18, tradução nossa). Essas características acima levam a um segundo eixo diagnóstico que se caracteriza por questões relativas à gestão, ao gerenciamento do curso, assim como à direção do departamento. Nesse sentido, a cisão dos departamentos e a consequente desarmonia entre os grupos componentes da instituição coagem uma dificuldade na gestão do binômio coordenação-departamento. Nada obstante é ressaltar acerca desse segundo eixo que algumas falas deram conta de dizer que os atores responsáveis pela gestão do binômio supracitado sempre fizeram o possível pela melhor gestão da instituição. Finalmente, o cenário descrito coage um terceiro eixo diagnóstico: problemas pedagógicos. Se o desconforto na instituição é generalizado, não escapa à regra o desconforto acadêmico; por exemplo, com alunos relatando um grau de sofrimento exacerbado, noites sem dormir para realização de trabalhos, relatos de falta de empatia entre alunos e docentes, falta de critérios definidos para as avaliações e a apelação discente à raiva como único afeto impulsionador da vida acadêmica.

Por conseguinte, a levar em conta os três eixos diagnósticos propostos acima, História e Cultura, Gestão e Pedagogia, foi proposta uma intervenção a ser realizada no segundo semestre de 2019 - a qual este relato não contempla - e que teve por objetivo favorecer um espaço de acolhimento e discussão do sofrimento inerente à existência na instituição. Em outras palavras, esta proposta diagnóstica visava favorecer a fala dos atores institucionais para, com isso, possibilitar a elaboração das questões dificultadoras do trabalho acadêmico e promover o bem-estar dos pertencentes à instituição. Assim, propuseram-se três atuações distintas que convergem em seu

\footnotetext{
${ }^{1}$ Consoante as construções teóricas de Pichon-Rivière (2005), toda escuta realizada pela Comissão partiu do pressuposto de que cada discurso colhido e acolhido pela equipe deveria ser considerado como um dado proveniente de um porta-voz da instituição. Na descrição do autor, "porta-voz é aquele que, no grupo, diz algo, enuncia algo em determinado momento, e esse algo é o sinal de um processo grupal que até esse momento permanecera latente ou implícito, como escondido no interior da totalidade do grupo. Como sinal, o que o porta-voz denuncia deve ser decodificado, ou seja, é preciso retirar seu aspecto implícito" (2005, p. 257).
} 
alvo: um Grupo Operativo para docentes; o apoio à gestão (coordenação e chefia); e oficinas pedagógicas para estudantes (focando na construção da função discente).

Especificando, cabe recordar que o Grupo Operativo é um instrumento de trabalho estudado por Pichon-Rivière (2005) e que se propõe construir um grupo em vistas à melhoria dos processos e da atuação de determinada tarefa; no caso de nosso processo ora em debate: o ser professor do curso analisado. Ademais, é importante ressaltar que tal tarefa não é simples, mas composta de inúmeros aspectos importantes, entre eles: o ser professor, o ser profissional, o que se espera do aluno na contemporaneidade, o fazer pedagógico, didática, o aluno idealizado versus o aluno real, entre outros. Em sequência, o apoio à gestão é uma intervenção pensada no formato de assessoria por parte da Comissão de Saúde Institucional para a gestão do curso e do departamento estudados. Ímpar afirmar, no entanto, que essa assessoria não é pensada como um "ensinar a fazer", mas um "aprender com" ou, ainda melhor, uma discussão das especificidades e elaboração das dificuldades inerentes à tarefa de gestão de um curso e de um departamento. Finalmente, a terceira etapa da intervenção proposta se refere ao alunado no que concerne às questões pedagógicas relativas ao fazer do aluno universitário, do amadurecimento necessário para estar num curso de graduação, entre outros aspectos.

\section{DEVOLUTIVAS E ANÁLISE}

À época da escrita deste relato de experiência, as entrevistas devolutivas já haviam sido realizadas, as etapas de "apoio à gestão", "grupo operativo" e de "oficinas discentes" foram autorizadas e estavam em fase de construção. Sobre as devolutivas, uma sentença proferida por um docente chamou a atenção: "Estou disposto a pagar o preço". Entendeu-se, por parte da Comissão, que essa frase fala das consequências do trabalho diagnóstico realizado, ela é um indicador avaliativo da tarefa desenvolvida. A sentença fora proferida por um docente na segunda de nossas entrevistas devolutivas e se assemelha a uma reorganização do sofrimento vivenciado pelos atores institucionais.

A primeira entrevista devolutiva foi realizada pela CSI em 04/07/2019 com a Diretoria de Graduação, o chefe do Departamento e o coordenador do Curso. Nessa devolutiva, a metodologia utilizada partiu da exposição dos objetivos gerais e específicos da Comissão, conforme pudemos descrever à época - a saber, objetivo geral: "estudar as relações construídas pelos atores institucionais no âmbito dos diversos setores da universidade"; objetivos específicos: "promover a saúde institucional por meio do trabalho diagnóstico e intervencionista" e "promover a saúde mental dos atores institucionais em seus diferentes setores" -, seguida da conceptualização de instituição utilizada como lente analítica do trabalho, exposição da linha temporal de nossa atividade e a metodologia do diagnóstico institucional. Em seguida, passou-se à apresentação da hipótese diagnóstica e, por fim, explanou-se sobre as propostas de intervenção. Em 08/07/2019 foram realizadas, em sequência, as devolutivas com o grupo de professores e com $o$ alunado.

Na reunião com os professores, poucos foram os pontos de resistência em relação à hipótese diagnóstica apresentada; resistência mínima que aparece como uma demanda por mais professores - conjecturando-se que esse é o único problema da instituição; e certa dificuldade em denotar o sofrimento aos membros da instituição - dizendo que os alunos dos últimos períodos são felizes quando percebem que se formarão. Ao final da explanação da hipótese diagnóstica, quase unanimemente os professores disseram concordar com os eixos elencados e parabenizaram a Comissão por conseguir sintetizar os sentimentos do grupo.

Outro aspecto que se pode escutar como avaliativo do trabalho realizado é quando outro docente diz sobre o "sofrimento" e o ressignifica ratificando que "sim, há sofrimento", mas que se deve usar isso para "seguir, lutar, ir em frente". Essas ressignificações parecem apontar para um dos efeitos do trabalho diagnóstico: seu efeito terapêutico. 0 fato de estarem sendo escutados, acolhidos em seu sofrimento, pode auxiliar os atores a se reconhecerem de uma maneira modificada, como sujeitos importantes da universidade; sujeitos em quem a instituição acadêmica, de certa forma, aposta e confia. Parece possível dizer, portanto, que o próprio trabalho diagnóstico já possibilitou um movimento, uma transformação.

Por parte das questões relativas à Comissão de Saúde Institucional, o trabalho supervisionado auxiliou sobremaneira a possibilidade de uma atuação ética e, na medida do possível, pautada na neutralidade dos membros quando da atuação com colegas servidores e discentes da instituição. Sobre isso, é importante dizer que existe uma divergência significativa entre a leitura de Bleger e Guirado daquilo que é possível de se fazer em Psicologia Institucional. Para Bleger (1984), a equipe executora do diagnóstico deve ser sempre exterior à instituição, como consultores. Já para Guirado, e uma vez que, tomando "a Psicologia Institucional [...] como método, como estratégia de pensamento, ao invés de tomá-la como mais uma área de atuação" (2009b, p. 331), aquele que atuar desde essa perspectiva pode, mesmo estando inserido na instituição, realizar apontamentos, cortes, intervenções necessárias e que promovam uma mudança institucional. Sua ação, portanto, "será institucional se esta for a perspectiva do trabalho" (Guirado, 2009b, p. 332). Cabe dizer, ainda, que entendemos a Psicologia Institucional como método, e mesmo um método clínico, considerando seu propósito investigativo "de desvendar os múltiplos sentidos dos fenômenos que são oferecidos à sua observação no espaço mais ou menos confinado de uma organização" (Acevedo, 2016, p. 18, tradução nossa). 
Com isso, a partir dessa experiência pudemos concluir que é possível a realização de um trabalho dessa especificidade por uma equipe construída com membros de uma mesma organização, porém com algumas ressalvas. Ressaltamos, entre elas, a importância do estudo teórico contínuo, reuniões permanentes da equipe executora e uma supervisão capacitada para que a equipe não se atrapalhe com o sintoma a ser estudado, não se identifique com o sofrimento e os fenômenos de grupo da instituição a ser diagnosticada. No caso em tela, pudemos contar com uma capacitação e supervisão externa à universidade, contudo é sabido que não poderá ser sempre assim. Dessa forma, cogita-se que em novos trabalhos sempre um membro fique não atuante no diagnóstico para servir de supervisor.

\section{CONSIDERAÇÕES FINAIS}

Depois de finalizada a primeira etapa da atuação descrita acima e instituída oficialmente a CSI desta IFES, é possível ratificar que esse foi um trabalho pioneiro nessa universidade, cujos desdobramentos trazem uma perspectiva de continuidade e possível ampliação. A leitura institucional de saúde proposta pela Comissão pretendeu favorecer as relações e significou pensar a chance de um trabalho com menos sofrimento e um ambiente institucional com maior qualidade de vida.

É fato que a academia possui pressões de diferentes qualidades e provenientes de inúmeros vetores, por isso a leitura institucional se torna assaz importante, porquanto favorece uma apreciação ampliada do objeto a ser estudado e exclui a busca contemporânea por culpados individualizados; a leitura institucional substitui essa busca pelo entendimento de que o sofrimento institucional é um sintoma de entraves relacionais. $E$, frente a isso, aposta na fala e na construção de bons discursos, um bem dizer a relação para o apaziguamento do sofrimento e a promoção de saúde.

\section{FINANCIAMENTO}

Não houve financiamento.

\section{DECLARAÇÃO DA CONTRIBUIÇÃO DOS AUTORES:}

Certificamos que todos os autores participaram suficientemente do trabalho para tornar pública sua responsabilidade pelo conteúdo. A contribuição de cada autor pode ser atribuída como se segue:

Mohr, Niada e Chiarello contribuíram para a conceitualização, investigação e metodologia; Albanese contribuiu para a supervisão; Mohr foi responsável pela redação inicial e final do artigo; Niada, Chiarello e Albanese foram responsáveis pela revisão do artigo.

\section{AGRADECIMENTOS}

Os autores agradecem aos demais membros da Comissão de Saúde Institucional e à IFES que autorizou o trabalho realizado.

\section{DECLARAÇÃO DE CONFLITOS DE INTERESSE}

Os autores declaram que não há conflitos de interesse no manuscrito submetido.

\section{REFERÊNCIAS BIBLIOGRÁFICAS}

Acevedo, M. J. (2016). Una psicologia institucional de perspectiva clínica. Subjetividad y Procesos Cognitivos, 20(2),17-40. http://dspace.uces.edu.ar:8180/xmlui/handle/123456789/3632

Bleger, J. (1984). Psico-Higiene e Psicologia Institucional. Porto Alegre: Artmed.

Brasil. (2005). Lei no 11.184, de 7 de outubro de 2005.

Freud, S. (1912/1996a). A dinâmica da transferência. In. Obras psicológicas completas de Sigmund Freud, vol. XII. Imago.

(1917 [1916-17]/1996b). Conferência XXVII: Transferência. In. Obras psicológicas completas de Sigmund Freud, vol. XVI. Imago.

Guirado, M. (2009a). A análise institucional do discurso como analítica da subjetividade. Tese de Doutorado. Instituto de Psicologia da Universidade de São Paulo.

(2009b). Psicologia Institucional: o exercício da psicologia como instituição. Interação em Psicologia, 13(2), 323333. http://dx.doi.org/10.5380/psi.v13i2

(2015). Clínica e transferência na sombra do discurso: uma analítica da subjetividade. Psicologia USP, 26(1), 108117. http://dx.doi.org/10.1590/0103-656420140022

Pichon-Rivière, E. (2005). O processo grupal. Martins Fontes.

Plut, S. (2016). Demanda y cierre de intervención en Análisis Institucional. Subjetividad y Procesos Cognitivos, 20(22), 70-90. http://dspace.uces.edu.ar:8180/xmlui/handle/123456789/3635

UTFPR-CT. (2019). Universidade Tecnológica Federal do Paraná - Campus Curitiba. Portaria do Diretor Geral n³96, de 17 de julho de 2019.

Viaro, R. V.; Guirado, M. \& Albanese, L. (2016). Subjetivação na formação em Psicanálise: uma análise institucional de discurso. Fractal: Revista de Psicologia, 28(2), 275-284. http:// dx.doi.org/10.1590/1984-0292/1185

Recebido em 24.08.2019 Primeira Decisão Editorial em 27.04.2020 Aceito em 16.06.2020 